$$
\begin{array}{r}
\text { Pontifícia Universidade Católica } \\
\text { do Rio de Janeiro }
\end{array}
$$

Marília de Araújo Barcellos

\title{
O SISTEMA LITERÁRIO BRASILEIRO ATUAL \\ Pequenas e médias editoras
}

\section{Tese de Doutorado}

Tese apresentada ao Programa de Pós-Graduação em Letras do Departamento de Letras da PUC-Rio como parte dos requisitos parciais para obtenção do título de Doutor em Letras.

Orientadora: Profa. Heidrun Friedel Krieger Olinto de Oliveira 


\section{Pontifícia Universidade Catálica $_{\text {a }}$ \\ DO RIO DE JANEIRO

Marília de Araújo Barcellos

\section{O SISTEMA LITERÁRIO BRASILEIRO ATUAL Pequenas e médias editoras}

Tese apresentada como requisito parcial para obtenção do grau de Doutor pelo programa de Pós-Graduação em Letras do Departamento de Letras do Centro de Teologia e Ciências Humanas da PUC-Rio. Aprovada pela Comissão Examinadora abaixo assinada.

Profa. Heidrun Friedel Krieger Olinto de Oliveira Orientadora Departamento de Letras - PUC-Rio

Profa. Pina Maria Arnoldi Coco Departamento de Letras - PUC-Rio

Profa. Daniela Gianna Claudia Beccaccia Versiani UNESA

Prof. Aníbal Francisco Alves Bragança Instituto de Arte e Comunicação Social - UFF

Prof. Fabio de Silos Sa Earp Instituto de Economia - UFRJ

Prof. Paulo Fernando Carneiro de Andrade

Coordenador Setorial do Centro de Teologia e Ciências Humanas - PUC-Rio

Rio de Janeiro, de de 
Todos os direitos reservados. É proibida a reprodução total ou parcial do trabalho sem autorização da universidade, da autora e da orientadora.

\section{Marília de Araújo Barcellos}

Graduada em Pedagogia pela PUC-RS (Pontifícia Universidade Católica do Rio Grande do Sul), em 1986. Mestre em Literatura Brasileira pela UFRGS (Universidade Federal do Rio Grande do Sul), em 2000. Participou de vários congressos e seminários sobre livro e história editorial; faz parte do Núcleo de Produção Editorial da Intercom - Sociedade Brasileira de Estudos Interdisciplinares da Comunicação; atuou no sistema literário como assessoria de imprensa, divulgação e editora de livros.

Ficha Catalográfica

Barcellos, Marília de Araújo

O sistema literário brasileiro atual pequenas e médias editoras / Marília de Araújo Barcellos ; orientadora: Heidrun Friedel Krieger Olinto de Oliveira. - Rio de Janeiro : PUC, Departamento de Letras, 2006.

149 f. ; $30 \mathrm{~cm}$

Tese (doutorado) - Pontifícia Universidade Católica do Rio de Janeiro, Departamento de Letras.

Inclui referências bibliográficas.

1. Letras - Teses. 2. Sistema literário. 3. Pequenas médias editoras. 4. Livro. 5. Mercado editorial. I. de Oliveira, Heidrun Friedel Krieger Olinto.. II. Pontifícia Universidade Católica do Rio de Janeiro. Departamento de Letras. III. Título. 


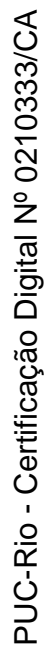

Para meu filho Moreno e meus pais. 


\section{Agradecimentos}

Escrever uma tese é sempre um trabalho solitário. Trata-se da imersão, dia após dia, em pesquisa, reflexão, análise, enfim, uma imensidão de decisões e procedimentos que fazem com que levemos a escrita sem deixar, em paralelo, a vida. É justamente nesses momentos, em que o mundo parece estar concentrado na feitura do texto, no desenvolvimento da idéia, nas dúvidas e incertezas, que as pessoas mais próximas têm papel essencial, pois se tornam imprescindíveis para a realização do trabalho, de um sonho; e a todas elas eu gostaria de agradecer.

$\mathrm{O}$ meu sincero obrigada à minha orientadora, Heidrun Krieger Olinto, que soube, com sua sensibilidade, conhecimento e experiência, perceber os rumos a serem tomados para a finalização da tese, após uma passagem difícil com que me deparei em meu trajeto de vida pessoal. A sua confiança e estímulo demonstraram o quanto o cognitivo e a emoção podem atuar em parceria para tornar superável a realização de uma tarefa.

Também agradeço aos professores com quem tive oportunidade de conviver no curso e que tanto me mostraram sobre o assunto literatura; estendo aos colegas que, juntos, permitiram tantos momentos de troca e amizade, em especial em torno do segmento da proposta da Revista escrita V e VI, para cuja preparação tivemos uma convivência tão proveitosa.

À comissão de Pós-Graduação, na gestão do professor Júlio Diniz, que conduziu questões acadêmicas de forma a me inserir, como representante discente, no universo burocrático e necessário para a vida acadêmica institucional.

Como não poderia deixar de ser, agradeço ao governo brasileiro, que me deu oportunidade de realizar meus estudos beneficiando-me com a bolsa CAPES/PROSUP, no Brasil, e CAPES/PDEE, na França.

Àqueles que compartilharam comigo e aos quais também pude ajudar a esclarecer as burocracias e caminhos de uma bolsa no estrangeiro. Muito tenho a ser grata à recepção dos colegas que conheci em Paris através de meu orientador de pesquisa na França, professor Jean Hébrard, cuja determinação, eficiência e 
simpatia apontaram direções e contribuíram para que a parte francesa do estudo fosse produtiva.

Gostaria de agradecer à banca examinadora: professores Aníbal Bragança, Daniela Versiani, Fábio Sá Earp e Pina Coco, que aceitaram o convite para participar, efetuar a leitura mas, principalmente, por contribuir de maneira construtiva na argüição e crítica do trabalho.

Meu obrigada também aos amigos e pares Luís Fernando Araujo, editor e amigo, Cristina Warth, pelos caminhos abertos; a Angelisa Stein, Eliane Paz e Teresa Bastos; e o meu obrigada especial a Alexandre Rodrigues Alves e Nilce Del Rio, por sempre saber poder contar com eles. A todos que acompanharam esta trajetória; aos livreiros, editores, estudantes que encontrei pelo caminho nessa estrada que só tem uma saída: os livros. 


\section{Resumo}

Barcellos, Marília de Araújo; de Oliveira, Heidrun Friedel Krieger Olinto (Orientadora). O SISTEMA LITERÁRIO BRASILEIRO ATUAL Pequenas e médias editoras. Rio de Janeiro, 2006. 149p. Tese de Doutorado - Departamento de Letras, Pontifícia Universidade Católica do Rio de Janeiro.

\section{O sistema literário brasileiro atual. Pequenas e médias editoras} investiga o universo do mercado editorial brasileiro a partir de pressupostos teóricos da literatura e para isso conta também com outras áreas - como sociologia e história -, que permitem perceber a inserção da produção literária e as relações que se estabelecem entre os agentes de produção, distribuição e recepção do campo literário. A tese aborda o tema sob o viés da literatura como complexo fenômeno cultural e social. Nesta ótica, à pesquisa da paisagem do sistema literário no Brasil - fundada em resultados da aplicação de entrevistas e questionários - foram agregadas importantes fontes de informação sobre outros mercados como a França, em que movimentos de concentração de grandes grupos, ou mesmo a existência de entidades de pequenos e médios editores, apontam para dinâmicas estratégicas ações características do mercado editorial atual. São analisados reflexos de fatores socioeconômicos e políticos na profisssionalização do setor, marcado simultaneamente pela expansão de megagrupos e pela união de editoras menores em vista de sua sobrevivência e para a ocupação de posição nesse mercado. A pesquisa abrange, ainda, a situação particular dessas pequenas e médias editoras a partir de sua definição de linha editorial, exibindo em seus catálogos um leque de direcionamentos, entre outros, quanto a ficção e/ou nãoficção, campo especializado e/ou diversificado, presença de autores nacionais e/ou estrangeiros, ou mesmo o registro de dados referentes às próprias empresas, como faturamento, época de fundação, localização, formação do editor, aspectos que, analisados em conjunto, ajudaram a compor o intricado circuito de produção, comercialização e recepção que marca o universo do livro no Brasil, mais especificamente no centro do país.

\section{Palavras-chave}

Sistema literário; pequenas médias editoras; livro; mercado editorial. 


\section{Abstract}

Barcellos, Marília de Araújo; de Oliveira, Heidrun Friedel Krieger Olinto (Advisor). The current Brazilian literary system. Small and medium publishing houses. Rio de Janeiro, 2006. 149p. PhD Dissertation Departamento de Letras, Pontifícia Universidade Católica do Rio de Janeiro.

The current Brazilian literary system. Small and medium publishing houses investigates the universe of the Brazilian publishing market departing from theoretic presuppositions from literature, along with other areas - like sociology and history -, which allow us to perceive the insertion of the literary production and the establishing relationship between the production, distribution and reception agents of the literary field. The thesis approaches the theme in the view of literature as a complex cultural and social phenomenon. Under such view, important sources of information about other markets (France for instance, where concentration movements by large groups, or even the existence of entities of small and medium editors, points to strategic actions that are characteristic to the current publishing market) are incorporated to the research - based on interviews and questionnaires - of the literary system in Brazil. In this thesis are analyzed the reflex of socio-economic and political factors in the professionalization of the sector, which is marked simultaneously by the expansion of mega groups and the joining of minor publishing houses for their survival and to keep their position in the market. The research also includes the particular situation of such small and medium publishing houses from the definition of their publishing lines, their catalogs showing a range of lines like fiction and/or non-fiction, specialized and/or diversified areas, national and/or foreign authors, or even the record of data about the companies like invoicing, time of foundation, location, the editor's education. Such aspects that when analyzed as a total helped in composing the intricate circuit of production, commercialization, and reception that identifies the book universe in Brazil, more specifically in the center of the country.

\section{Keywords}

Literary system; small medium publishing houses; book; publishing market. 


\section{Sumário}

$\begin{array}{ll}\text { Introdução } & 13\end{array}$

2. Sistema Social Literatura 16

2.1. Ação de Mediação 19

3. Grandes Editoras $\quad 30$

3.1. Tendências de Concentração 36

3.2. Políticas Governamentais $\quad 55$

3.3. O Cenário Editorial na França 66

4. Pequenas e Médias Editoras 103

4.1. Libre 105

4.2. Agentes 114

4.3. Pesquisa 118

$\begin{array}{ll}\text { Considerações Finais } & 134\end{array}$

Referências Bibliográficas $\quad 136$

$\begin{array}{ll}\text { Anexo } & 144\end{array}$ 


\section{Lista de Figuras}

$\begin{array}{ll}\text { Figura } 1 \text { - Sistemas } & 17\end{array}$

Figura 2 - Mercado de política de publicação de vendas orientadas $\quad 21$

Figura 3 - Seleção das idéias do produto $\quad 22$

$\begin{array}{lr}\text { Figura } 4 \text { - Campo literário } & 28\end{array}$

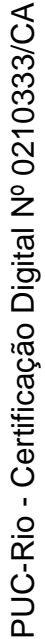




\section{Lista de Quadros}

Quadro 1: Analfabetismo $\quad 32$

Quadro 2: Títulos traduzidos e autores nacionais, de 2000 a 2004.

Quadro 3: Produção e vendas do setor editorial brasileiro, de 2000 a $2004 \quad 58$

Quadro 4: Títulos produzidos nos subsetores entre 2000 e 2004

Quadro 5: Histórico de acordos comerciais e Lei preço único 85

Quadro 6: países que não implantaram o preço único para o livro 85 


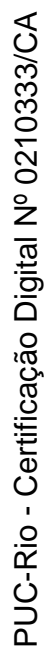

Quisera eu ter em meu texto, A leveza anunciada por Ítalo Calvino... 